\title{
Personalising Pollution Exposure Estimates Using Wearable Activity Sensors
}

\author{
Ke $\mathrm{Hu}^{* 1}$, Yan Wang ${ }^{* 2}$, Ashfaqur Rahman ${ }^{\dagger 3}$ and Vijay Sivaraman*4 \\ ${ }^{*}$ School of Electrical Engineering and Telecommunications, University of New South Wales, Sydney, Australia \\ ${ }^{\dagger}$ Intelligent Sensing and Systems Laboratory, CSIRO, Hobart, Australia \\ ${ }^{1}$ ke.hu@student.unsw.edu.au, ${ }^{2}$ oscarwang1205@gmail.com, ${ }^{3}$ ashfaqur.rahman@ csiro.au, ${ }^{4}$ vijay@unsw.edu.au
}

\begin{abstract}
In recent years several research groups, including ours, have demonstrated participatory systems that use wearable or vehicle-mounted portable units coupled with smartphones to crowdsource urban air pollution data from lay users. These systems have shown remarkable improvement in spatial granularity over government-operated monitoring systems, leading to better mapping and understanding of urban air pollution, at relatively low cost. In this paper we extend the paradigm to personalize the consumption of data by individuals. Specifically, we combine the pollution concentrations obtained from participatory systems with the individual's on-body activity monitors to estimate the personal inhalation dosage of air pollution. We show that the individual's activity, such as jogging, cycling, or driving, impacts their dosage, and develop an app that gives them this personalised information. Our system is a step towards enabling medical inferencing of the impact of air pollution on individual health.
\end{abstract}

Keywords—pollution sensor; activity monitor; mobile apps

\section{INTRODUCTION}

Air pollution imposes a heavy burden on human health. The World Health Organisation (WHO) estimates [1] that every year several million people world-wide die prematurely from air pollution induced diseases such as chronic obstructive respiratory disease (COPD). Therefore, monitoring and controlling ambient air pollution is high on the public consciousness in both developing and developed countries.

Several medical studies [2]-[7] have shown that air pollution has adverse impact on human health. However, these studies consider aggregates of populations, and use coarse data on pollution levels, often at the city or suburb level, taken from traditional fixed monitoring sites operated by governments. The poor spatial resolution of such data often ignores the variations in air pollution levels across a neighbourhood (e.g. due to different land use and roads), and does not therefore lend itself to inferences at the individual level. In recent years, with the rapid growth of portable sensors, several studies have tried to use participatory sensing and crowdsourcing systems to get fine-gained urban air pollution data [8]-[12], including the system we have developed and operate as described in [13] (we note that data quality assessment mechanisms such as the one we developed in [14] are improving the reliability of the data collected from such systems).

In this paper, we leverage the increased spatial granularity of air pollution data obtained from participatory systems, and try to personalise the information for an individual so that better medical inferences can be made at the individual level.
As an example, consider two individuals who are both in the same place at the same time, but one is driving while the other is jogging. They will experience the impact of air pollution in different ways since they will inhale different amounts due to their different breathing rates, and may additionally have different medical predispositions to the exposure. When these differences are accumulated over a long period, they can become significant, leading to different health outcomes. In this study therefore we combine ambient pollution levels (taken from our participatory system) with an individual's activity levels to estimate the personal inhalation dosage, which can then be used to make further medical inferences for that individual. Our specific contributions are:

1) We develop a system for estimating personal air pollution inhalation dosage. Our system comprises a mobile app that interfaces with wearable personal activity sensors to determine breathing rate, and combines it with ambient pollution concentration determined from our participatory pollution monitoring system.

2) We conduct field trails with our system in Sydney, and obtain real-time pollution inhalation dosage estimates showing that different levels of activity (driving, cycling, and jogging) entail very different levels of exposure. The improved estimates from our system compared to earlier systems that do not include personal activity information allow for more accurate medical inferencing.

The rest of this paper is organized as follows: Section II discusses prior work relevant to this paper. In Section III we describe our system and methods used in our study. In Section IV we present results from trials in Sydney, and the paper concludes in Section V.

\section{RELATED WORK}

Several projects have emerged over the past few years that attempt to crowdsource data from low-cost portable mobile sensors to obtain air pollution estimates of high spatial granularity. Notable ones include the MESSAGE (Mobile Environmental Sensing System Across Grid Environments) project [15] in the UK, the MAQUMON project [16] from Vanderbilt University, the CommonSense project [17] supported by Intel, and the OpenSense project [18] ongoing at EPFL Switzerland. Our group also operates a system that we call "HazeWatch" [13] that monitors and maps Sydney air pollution in real time 


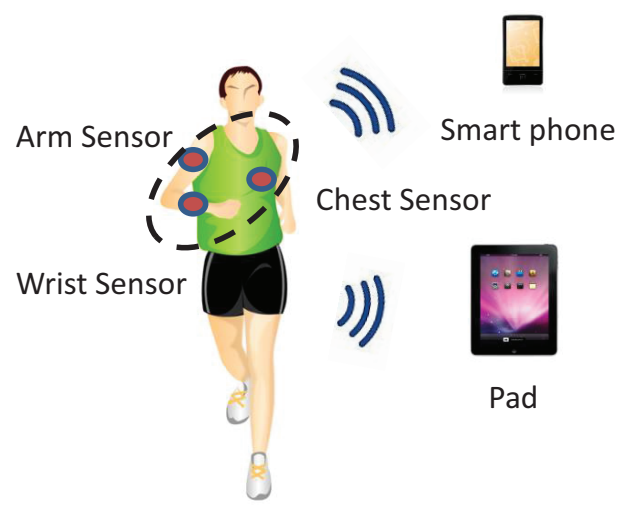

1.Wireless sensor network

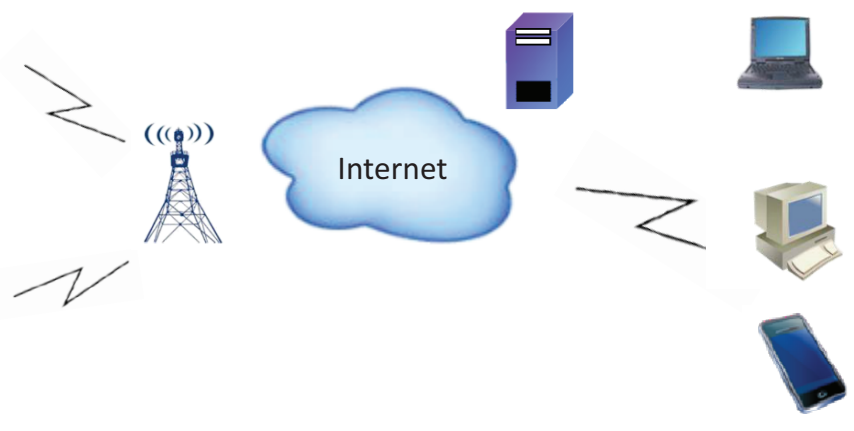

2.Data Centre
3.User interface

Fig. 1. System Architecture

via vehicle-mounted pollution sensors using both custom-built and off-the-shelf hardware. To the best of our knowledge, these systems focus on gathering the pollution data, and not so much on consumption of data by individuals in a personalised way.

There also exist studies in the literature that try to associate human activity levels with pollution exposure concentrations. For example, the studies in [19], [20] use physical activity times to estimate personal exposure, and its effect on Ischemic Heart Disease Mortality. However, these studies only use the user's home location to estimate their exposure, without regard to the mobility pattern of the individual. In [21] the authors develop a tool called CalFit that records the individual's location and activity information. However, their study did not use participatory sensor networks, and instead relied on historical data from fixed monitor sites and derived exposure estimates based on an Atmospheric Dispersion Modelling System (ADMS). As we will show in the paper, using data with such low spatial density can lead to incorrect exposure estimates and hence biased medical inferences.

Several studies have involved volunteers carrying portable pollution monitors. For example, the authors of [22] designed a study to find out the impact of time-activity patterns on personal exposure. They followed sixteen participants, obtaining their temporal-spatial information with a PDA, and black carbon concentrations with a potable monitor. Their results showed that transportation contributed the highest black carbon concentrations. Nevertheless, their study ignored the human activity levels and only estimated the pollution concentration around the participants rather than their personal inhaled dosage.

A research group in Barcelona, Spain designed a survey that tried to compare the exposures with different travel modes in [23] which is very much aligned with our objectives. They asked commuters to use different transport modes going along the same route to find out their relative inhalation dose. The inhalation rate algorithm they used was developed by other researchers, which assumed that inhalation rate ratio between different travel modes were constants. We believe that their referenced inhaled dose were hence neither real-time nor sufficiently accurate.
Parallel to our work, authors in [24] discussed how to combine individual time-activity patterns and air pollution concentrations, and gave a model to integrate the data. In [25], the author designed a system called ExposureSense which can combine smart phone accelerometer, external air quality data and pluggable sensors for personal pollution exposure estimation. In these two papers, only personal location and acceleration information were considered as activity data, which can estimate the ambient air pollution concentrations, instead of personal real-time inhaled dose.

\section{System COMPONENTS AND Methods}

\section{A. System architecture}

We demonstrate a novel system consisting of various wearable sensors, mobile applications and data center, which can allow real-time feedback of user's exposure dose. Such a system can be used in personal exposure estimation, and estimation of impact of air pollution on human health. As shown in Fig. 1, the system is based on a horizontal structure with 3 levels.

1) Level 1:Wireless sensor network: integrates sensors and applications to collect and upload data. It can be divided into two parts: sensors and applications.

Sensors: Various wearable sensors integrate different kinds of potable air pollution, activity and medical sensors to sample physiological and environment data. For air pollution sensing, we use the NODE wireless sensor platform which supports connection to iOS and Android smart phones. As shown in Fig. 2(a), the NODE sensor platform is designed with plug-in modules mode. It comprises body platform part and interchangeable OXA gas sensor header part. With changing the OXA headers, Carbon Monoxide (CO), Nitric Oxide (NO), Nitrogen Dioxide (NO2) and other three pollutants can be monitored. We only monitor Carbon Monoxide (CO) in this study, as $\mathrm{CO}$ is one of the most important pollutants all over the world, and it may cause many diseases, like arteriosclerosis and lung disease. Smart phones can connect to the body platform with bluetooth 4.0 up to 250 feet away. The cost of NODE device is about $\$ 150$ for body platform and $\$ 150$ for one OAX header each. 


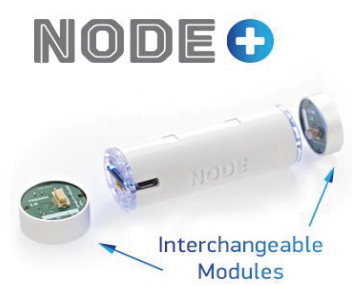

(a) NODE sensor [26]

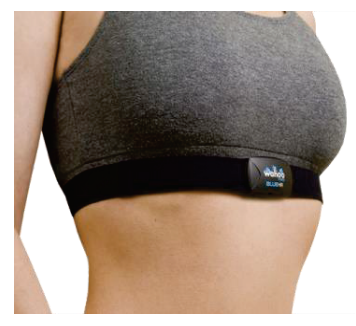

(b) Wahoo heart rate monitor [27]

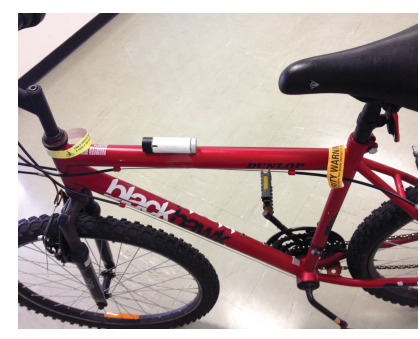

(c) NODE sensor on a bike

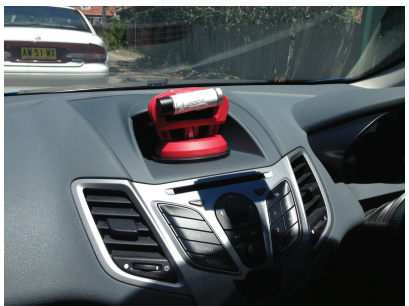

(d) NODE sensor in a car

Fig. 2. (a)NODE platform body and header modules (b)Sample of how to wear Wahoo heart rate monitor (c)Attached NODE on a bike and (d)in a car

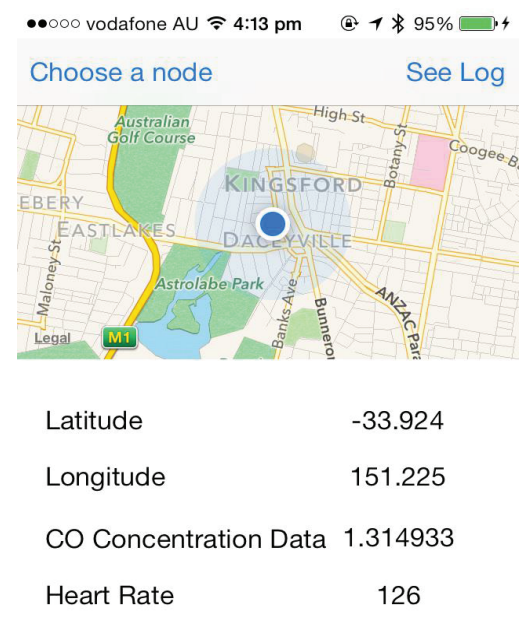

00:14:25

(a) iPhone upload application

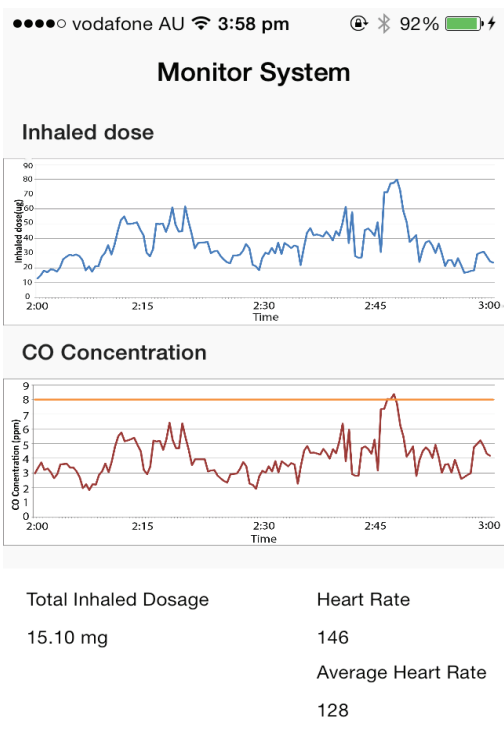

(b) iPhone user application

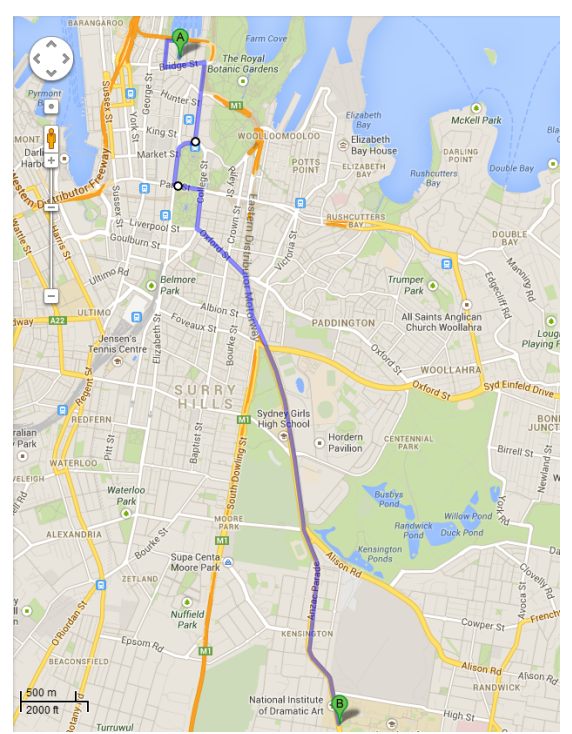

(c) Trip route

Fig. 3. (a)Trip route monitored for 3 activity modes (b)Application to upload pollution and heart rate data (c)Application showing personal inhaled dose

As inhaled dose refers to respiratory rate, which is related to heart rate, we use Wahoo heart rate monitor to get heart rate readings. Wahoo heart rate monitor can track user's heart rate data in real-time with wearing it around chest which is shown in Fig.2(b). It supports bluetooth 4.0 to connect to iOS smart phones and Pad.The cost of one Wahoo heart rate monitor is $\$ 80$.

Applications: We developed an iPhone app to connect with both NODE sensors and Wahoo heart rate sensors using published APIs. It allows user to pair their iPhone with sensors over bluetooth and get real-time data. For NODE sensors, we can get raw air pollution data from the API. PPM values can be calculated by the following equation:

$$
P P M=\frac{\text { Raw_Reading }-C O \_ \text {Base_Line }}{0.37736 \times\left(C O \_ \text {Gain } \times \text { CO_Ratio }\right)} \times 10^{9},
$$

where $\mathrm{CO}_{-}$Base_ Line denotes calibration base line and can be calculated by NODE official iPhone app. After being calibrated, the $\mathrm{CO}$ _ Base _ Line value can be written in the server, and the app can update calibration value for a regular time. $\mathrm{CO}_{-}$Gain and $\mathrm{CO}_{-}$Ratio are constants and the values are 35000 and 39 respectively.
Also, the app will track the location data of users. All GPS data collection rely on mobile phones. For example, Fig. 3(a) shows a screen-shot of our application interface. Upon connecting with the selected sensors, it will constantly sample, upload and display the information as current location on a map, the GPS information, $\mathrm{CO}$ concentration and heart rate after starting recording. Recording time will also be displayed on the screen.

2) Level 2:Data center: is the server of whole system. It stores and processes the data.

This is the central repository, to which our data contributor users automatically upload air pollution and heart rate data into a MySQL database. For protection of privacy, the system will not share heart rate information with other users. Since no system can measure pollution in all time and spatial levels, we use two interpolation model to estimate the $\mathrm{CO}$ concentrations all over Sydney, one being inverse distance weighting (IDW) and the other being ordinary kriging.

3) Level 3:User interface: this empowers the user with the tools to obtain their personal exposure and health data.

We developed an iPhone application for users to can track their heart rate and ambient environment exposure, and thereby 
TABLE I. EXPERIMENT ATtRIBUtes

\begin{tabular}{||cccccc||}
\hline & Heart rate(bpm) & Real - time RMV (Lmin $\left.{ }^{-1}\right)$ & Constant RMV (Lmin ${ }^{-1}$ ) & \multicolumn{2}{c|}{ CO concentration(ppm) } \\
\hline & & & & Duration(min) \\
& & & & Government \\
fixed-site (FS) & $\begin{array}{l}\text { Participatory } \\
\text { system (PS) }\end{array}$ \\
\hline Jogging & $153.2(75-172)$ & $46.4(22.7-52.1)$ & 12 & 0.19 & $4.0(1.1-8.4)$ \\
Bicycling & $123(76-146)$ & $30.7(19-36.5)$ & 12 & 0.19 & $6.1(1.3-18)$ \\
Driving & $84.9(77-93)$ & $14.1(12.8-15.5)$ & 12 & 0.19 & $6.9(1.7-34.7)$ \\
\hline
\end{tabular}

determine their inhaled dose. This personalization is for users who wear an activity (heart rate) monitor; carrying an air pollution sensor is optional, as the latter can be obtained from data contributed by others in our participatory monitoring system. For example, in Fig. 3(b) we show a screen-shot of the dosage graph, showing that how the $\mathrm{CO}$ inhalation dose varied over time while the user was jogging between approximately $2 \mathrm{pm}$ to $3 \mathrm{pm}$. The graph also shows the user with CO concentrations around him/her and how his/her exposure comparing with a long-term healthy guide line which is guided by WHO via a orange line.

\section{B. Experiments}

An initial personal exposure measurements took place in Sydney in August 2013. Three participants were asked to carry heart rate sensors and air pollution sensors and take three different activity modes (jagging, bicycling and driving) along a certain route as shown in Fig.3(c). The route starts at Jessie Street Gardens, travels through Hyde Park going along Macquarie Street, and ends at the main gate of the University of New South Wales, comprising a total distance of $7.6 \mathrm{~km}$. This route has a bike lane parallel to the roads, and encounters varying traffic conditions along the road including frequent traffic jams.

\section{Carbon monoxide measurements}

$\mathrm{CO}$ concentrations data are from two different sources. One is from our Hazewatch participatory sensing system (for brevity, referred to henceforth as PS) [13]. Fig. 2(c) and Fig. 2(d) show how we attach the NODE sensors in a car and on a bike. All NODE sensors were calibrated by its official software 3 days before the study. To compare with the fixedsite (for brevity, referred to henceforth as FS) air pollution data, we also include six fixed monitoring sites data published by the Office of Environment and Heritage in NSW, Australia. Inverse Distance weighting(IDW) interpolation model is used to calculate $\mathrm{CO}$ concentrations along the survey route.

\section{Inhalation dose measurements}

Respiratory minute volume (RMV) refers to the inhaled volume of air into a person's lung per minute. In this experiment, real-time RMV is calculated from heart rate with a random population based algorithm developed in [28], whereby the ratio heart-rate (beats per minute) : RMV (L/min) in [jogging, bicycling, driving] $=[3.3: 1,4: 1,6: 1]$. For baseline comparisons in which activity levels are not available, we use a typical RMV of $12(\mathrm{~L} / \mathrm{min})$ based on prior research [29].
The inhaled dose of pollutant is then calculated as follows:

$$
\begin{aligned}
\text { Inhaled_dose }= & \text { Respiratory_minute_volume } \\
& \times \text { CO_concentration } \times \text { time } \\
& \times \text { conversion_factor },
\end{aligned}
$$

where the $\mathrm{CO}$ concentration unit is ppm and conversion factor for carbon monoxide is $1.145 \mu \mathrm{g} / \mathrm{L}$.

\section{RESUlts AND DiscusSION}

Table I shows the attributes of the experimental study, including the measures heart rates of the participants, the respiratory minute volume (RMV), CO pollution concentrations, and the experiment duration. In Table II we summarize the inhaled dose estimation results of our experiments, while Fig. 4 shows the details for the three different activity modes considered in this study.

\section{A. CO concentrations}

$\mathrm{CO}$ concentration data from the fixed monitoring site (FS), as shown in Table I, is constant and very low. The poor spatial resolution of such data implies that the distance from monitoring sites to our route in this experiment is very far; indeed the two closest monitoring sites are Chullora and Rozelle, respectively $15 \mathrm{~km}$ and $20 \mathrm{~km}$ from our route. Furthermore, the other four sites range $30-50 \mathrm{~km}$ far from our route. The mean CO concentrations obtained from fixed-sites is $0.19 \mathrm{ppm}$ irrespective of the activity mode.

On the other hand, ambient $\mathrm{CO}$ concentration data from our participatory system show significant variation, with pollution peaking along the traffic jam section, and reaching a high level $($ jogging $=8.4$; bicycling $=18$; driving $=34.7 \mathrm{ppm}$ ). The mean $\mathrm{CO}$ concentrations for three different activity modes is (jogging $=4.0$; bicycling $=6.1$; driving $=6.9$ ), from which we observe that $\mathrm{CO}$ concentrations are significantly higher for driving compared to jogging and bicycling, since $\mathrm{CO}$ concentrations drop as one moves away from the centre of the road. For example, in the same location, the $\mathrm{CO}$ concentrations is $8.2(\mathrm{ppm})$ in the center of the road, and with $6.1(\mathrm{ppm})$ and $3.4(\mathrm{ppm})$ along the cycleways and sidewalk. This is consistent with our expectation that on-road drivers will experience higher pollution concentrations that off-road bicyclists and joggers.

\section{B. Respiratory Minute Volume (RMV)}

From Table I, we see that joggers have higher mean heartrate $(153.2 \mathrm{bpm})$ than bicyclists $(123 \mathrm{bpm})$, who in turn have higher heart-rate than drivers $(84.9 \mathrm{bpm})$. Consequently, the RMV is higher for joggers (46.4) compared with bicyclists (30.7) and drivers (14.1). 
TABLE II. INHALATION DOSAGE FOR DIFFERENT ACTIVITY MODES

\begin{tabular}{|c|c|c|c|c|c|c|c|c|}
\hline & \multicolumn{4}{|c|}{ Inhaled dose $\left(\mu \mathrm{g} \min ^{-1}\right)$} & \multicolumn{4}{|c|}{ Total inhaled dose $(\mu \mathrm{g})$} \\
\hline & $\begin{array}{l}\text { FS CO data + } \\
\text { constant RMV }\end{array}$ & $\begin{array}{l}\text { FS } \mathrm{CO} \text { data } \\
+\quad \text { real-time } \\
\mathrm{RMV}\end{array}$ & $\begin{array}{l}\text { PS CO data }+ \\
\text { constant RMV }\end{array}$ & $\begin{array}{l}\text { PS } \mathrm{CO} \text { data } \\
+\quad \text { real-time } \\
\mathrm{RMV}\end{array}$ & $\begin{array}{l}\text { FS CO data + } \\
\text { constant RMV }\end{array}$ & $\begin{array}{l}\text { FS } \mathrm{CO} \text { data } \\
+\quad \text { real-time } \\
\text { RMV }\end{array}$ & $\begin{array}{l}\text { PS CO data + } \\
\text { constant RMV }\end{array}$ & $\begin{array}{l}\text { PS } \mathrm{CO} \text { data } \\
+\quad \text { real-time } \\
\mathrm{RMV}\end{array}$ \\
\hline Jogging & $2.6(2.5-2.6)$ & $10.0(4.9-11.4)$ & $\begin{array}{l}55.3(25.3- \\
115.1)\end{array}$ & $\begin{array}{l}215.5(77.3- \\
479.5)\end{array}$ & 165.7 & 642.2 & 3540.2 & 15037.8 \\
\hline Bicycling & $2.6(2.5-2.6)$ & $6.6(4.1-8.0)$ & $\begin{array}{l}84.4(17.3- \\
247.2)\end{array}$ & $\begin{array}{l}220.3(36.8- \\
690.1)\end{array}$ & 106.2 & 272.2 & 3459.2 & 9031.5 \\
\hline Driving & $2.6(2.5-2.6)$ & $3.1(2.7-3.4)$ & $\begin{array}{ll}94.3 & (22.9- \\
477.2) & \\
\end{array}$ & $\begin{array}{l}114(25.1- \\
563.3)\end{array}$ & 72.5 & 85.5 & 2640.7 & 3767.1 \\
\hline
\end{tabular}

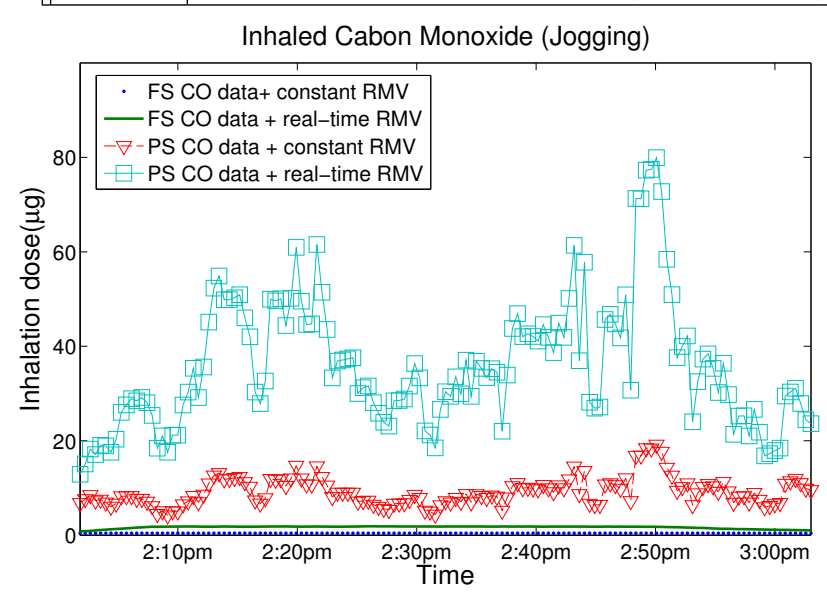

(a)

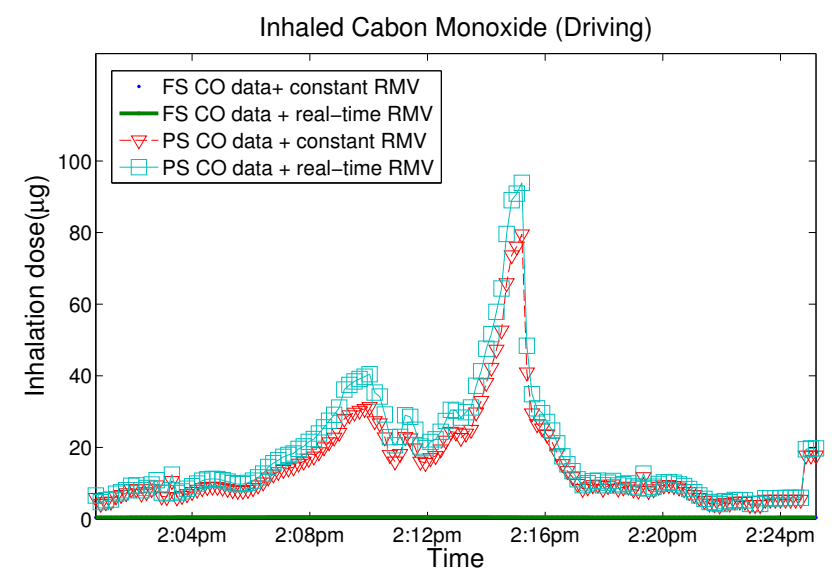

(c)

Fig. 4. Carbon monoxide inhalation dosage

\section{Inhaled dose}

The aggregate inhaled dose quantities are shown in Table II, while the detailed time-series are shown in Figs. 4(a), 4(b) and 4(a). The table compares how using real-time RMV improves the estimate compared to assuming a constant RMV. We see that with fixed-site (FS) CO concentrations and constant RMV, inhaled dose is very low $\left(2.6 \mu \mathrm{g} \mathrm{min}{ }^{-1}\right)$ and flat for different activity modes. When we use real-time RMV along with fixed-site $\mathrm{CO}$ concentrations, jogging inhaled dose increases to $10\left(\mu \mathrm{g} \mathrm{min}{ }^{-1}\right)$. Moving further in the table, when $\mathrm{CO}$ concentrations from our participatory system (PS) are used assuming a constant RMV, the inhaled dose per minute significantly increases, and shows that driving incurs highest inhaled dose $\left(94.3 \mu \mathrm{g} \mathrm{min}^{-1}\right)$, more than bicycling $\left(84.4 \mu \mathrm{g} \mathrm{min}^{-1}\right)$

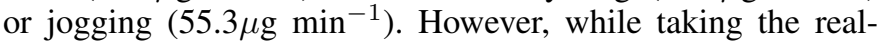

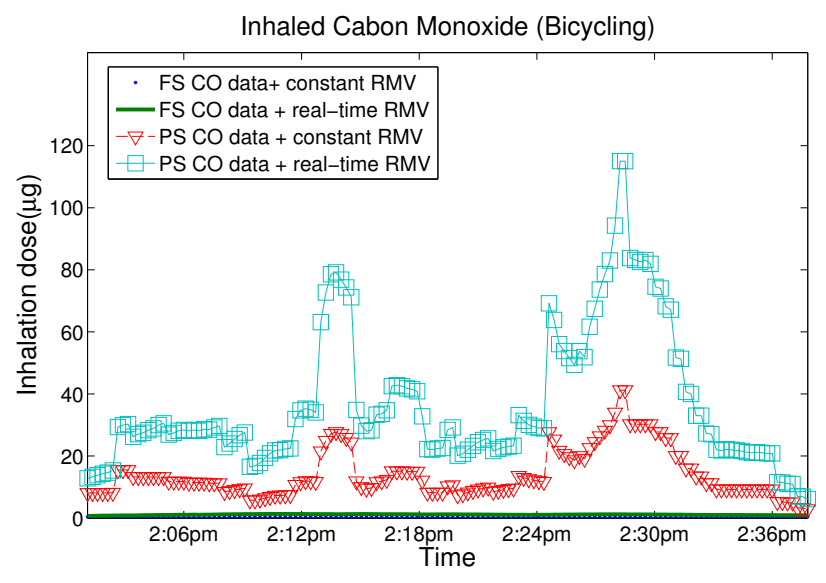

(b)

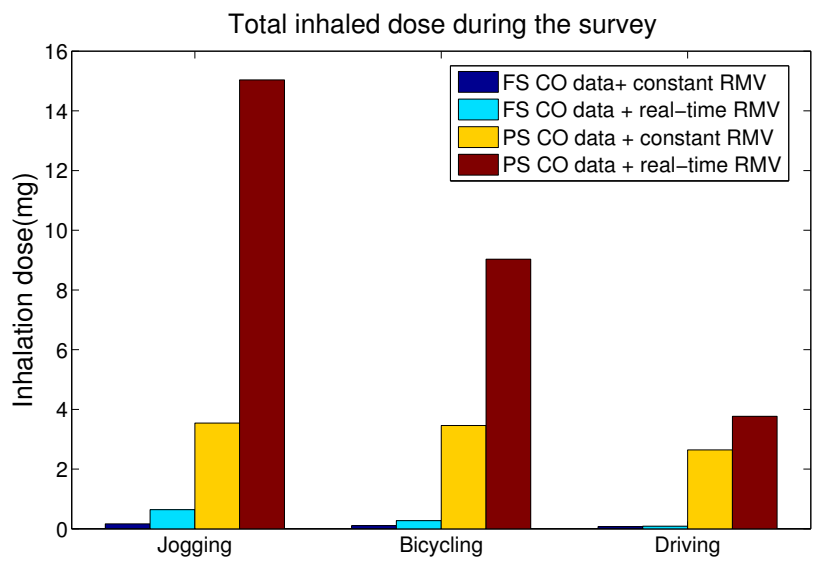

(d)

time RMV into consideration along with pollution from our PS system, the situation reverses - the jogger's inhaled dose per minute increases to $215.5\left(\mu \mathrm{g} \mathrm{min}{ }^{-1}\right)$, while driving is lower at $114\left(\mu \mathrm{g} \mathrm{min}{ }^{-1}\right)$. This illustrates that while jogging off-road reduces the pollution concentration, the pollution intake dosage is actually higher due to increased breathing rate, compared to driving. Interestingly, bicycling turns out to be even worse than jogging, probably because it happens closer to the road than jogging, while having a high heart-rate. In Fig. 4(d), we show total dosage for making the trip using the three activity modes, from which we can conclude that jogging entails the highest inhaled dose $(15037.8 \mu \mathrm{g})$, followed by bicycling $(9031.5 \mu \mathrm{g})$, and driving the least $(3767.1 \mu \mathrm{g})$. This is not surprising, since bicyclists and joggers get exposed for longer duration while traversing teh same distance, compared to drivers. 


\section{CONCLUSION AND FUture WORK}

In this paper we have presented a novel system for estimating personal air pollution inhalation dosage. The system incorporates portable air pollution sensors, wearable human activity sensors, data center storage, and mobile applications. Our initial field trials in Sydney indicate that our system can more accurately estimate individual air pollution inhalation dosage. Earlier studies had either ignored activity levels, or concluded that jogging or bicycling entail lower exposure, but our study shows that this need not always be the case.

In this article, air pollution data is only collected by our participants who also wear the activity sensors. Future work will consider individuals wearing activity sensors who will benefit from the fine-gained air pollution data collected by other participants. For example, a relatively small of users may carry air pollution sensors and contribute air pollution data, while other participants who only wear activity sensors can benefit from the data, and be empowered by our apps to manage their real inhaled dose. We hope to conduct more extensive experiments with our system in the coming months to quantify the personalised impact of air pollution exposure and aid in making better medical inferences.

\section{REFERENCES}

[1] World-Health-Organization, "Air Pollution." [Online]. Available: http://www.who.int/topics/air_pollution/en/

[2] I. Beverland, C. Robertson, C. Yap, M. Heal, G. Cohen, D. Henderson, C. Hart, and R. Agius, "Comparison of models for estimation of long-term exposure to air pollution in cohort studies," Atmospheric Environment, vol. 62, pp. $530-539,2012$.

[3] L. M. McKenzie, R. Z. Witter, L. S. Newman, and J. L. Adgate, "Human health risk assessment of air emissions from development of unconventional natural gas resources," Science of The Total Environment, vol. 424, pp. 79 - 87, 2012.

[4] R. Allen, E. Gombojav, B. Barkhasragchaa, T. Byambaa, O. Lkhasuren, O. Amram, T. Takaro, and C. Janes, "An assessment of air pollution and its attributable mortality in ulaanbaatar, mongolia," Air Quality, Atmosphere and Health, vol. 6, pp. 137 - 150, 2013.

[5] G. Hoek, S. Pattenden, S. Willers, T. Antova, E. Fabianova, C. BraunFahrlnder et al., "Pm10, and children's respiratory symptoms and lung function in the paty study," European Respiratory Journal, vol. 40, pp. $538-47,2012$.

[6] M. Franklin, H. Vora, E. Avol, R. McConnell, F. Lurmann, F. Liu, B. Penfold, K. Berhane, F. Gilliland, and W. J. Gauderman, "Predictors of intra-community variation in air quality," Journal of Exposure Science and Environmental Epidemiology, vol. 22, pp. 135 - 47, 2012.

[7] J. Heinrich, E. Thiering, P. Rzehak, U. Krmer, M. Hochadel, K. M Rauchfuss, U. Gehring, and H.-E. Wichmann, "Long-term exposure to no2 and pm10 and all-cause and cause-specific mortality in a prospective cohort of women," Occupational and Environmental Medicine, vol. 70 , pp. $179-86,2013$.

[8] S. Kanhere, "Participatory sensing: Crowdsourcing data from mobile smartphones in urban spaces," in Distributed Computing and Internet Technology, ser. Lecture Notes in Computer Science, 2013, vol. 7753.

[9] Z. Yan, J. Eberle, and K. Aberer, "Optimos: Optimal sensing for mobile sensors," in Proceedings of the 2012 IEEE 13th International Conference on Mobile Data Management (Mdm 2012), Washington, DC, USA, 2012

[10] A. Kadri, E. Yaacoub, M. Mushtaha, and A. Abu-Dayya, "Wireless sensor network for real-time air pollution monitoring," in Communications, Signal Processing, and their Applications (ICCSPA), 2013 1st International Conference on, 2013.

[11] M. Mead, O. Popoola, G. Stewart, P. Landshoff, M. Calleja, M. Hayes, J. Baldovi, M. McLeod, T. Hodgson, J. Dicks, A. Lewis, J. Cohen, R. Baron, J. Saffell, and R. Jones, "The use of electrochemical sensors for monitoring urban air quality in low-cost, high-density networks," Atmospheric Environment, vol. 70, pp. 186 - 203, 2013.

[12] S. Devarakonda, P. Sevusu, H. Liu, R. Liu, L. Iftode, and B. Nath, "Realtime air quality monitoring through mobile sensing in metropolitan areas," in Proceedings of the 2Nd ACM SIGKDD International Workshop on Urban Computing, New York, NY, USA, 2013.

[13] V. Sivaraman, J. Carrapetta, K. Hu, and B. Gallego Luxan, "Hazewatch A participatory sensor system for monitoring air pollution in sydney," in IEEE SenseApp (co-located with IEEE LCN), Sydney, Australia, Oct. 2013

[14] A. Rahman, D. Smith, and G. Timms, "Multiple classifier system for automated quality assessment of marine sensor data," in Intelligent Sensors, Sensor Networks and Information Processing, 2013 IEEE Eighth International Conference on, 2013.

[15] M. Mead, O. Popoola, G. Stewart, P. Landshoff, M. Calleja, M. Hayesb, J. Baldovi, M. McLeod, T. Hodgson, J. Dicks, A. Lewis, J. Cohen, R. Baron, J. Saffell, and R. Jones, "The Use of Electrochemical Sensors for Monitoring Urban Air Quality in Low-Cost, High-Density Networks," Atmospheric Environment, vol. 70, pp. 186-203, May 2013.

[16] P. Vlgyesi, A. Ndas, X. Koutsoukos, and . Ldeczi, "Air Quality Monitoring with SensorMap," in Proc. Intl. Conf. Information Processing in Sensor Networks (IPSN), St. Louis, MO, USA, Apr 2008. [Online]. Available: http://www.isis.vanderbilt.edu/projects/maqumon

[17] P. Dutta, P. Aoki, N. Kumar, A. Mainwaring, C. Myers, W. Willett, and A. Woodruff, "Common Sense: Participatory Urban Sensing Using a Network of Handheld Air Quality Monitors," in Proc. SenSys Demonstration, Berkeley, CA, USA, Nov 2009. [Online]. Available: http://www.communitysensing.org/

[18] K. Aberer, S. Sathe, D. Chakraborty, A. Martinoli, G. Barrenetxea, B. Faltings, and L. Thiele, "OpenSense: Open Community Driven Sensing of Environment," in Proc. ACM SIGSPATIAL Intl. Workshop on GeoStreaming (IWGS), San Jose, CA, USA, Nov 2010, p. Nov. [Online]. Available: http://opensense.epfl.ch

[19] S. Hankey, J. D. Marshall, and M. Brauer, "Health impacts of the built environment: within-urban variability in physical inactivity, air pollution, and ischemic heart disease mortality," Environ Health Perspect, vol. 120 , pp. $247-53,2012$.

[20] O. Raaschou-Nielsen and et al, "Air pollution and lung cancer incidence in 17 european cohorts: prospective analyses from the european study of cohorts for air pollution effects (escape)," The Lancet Oncology, vol. 14 , pp. 813-822, 2013.

[21] A. de Nazelle, E. Seto, D. Donaire-Gonzalez, M. Mendez, J. Matamala, M. J. Nieuwenhuijsen, and M. Jerrett, "Improving estimates of air pollution exposure through ubiquitous sensing technologies," Environmental Pollution, vol. 176, pp. 92 - 99, 2013.

[22] E. Dons, L. I. Panis, M. V. Poppel, J. Theunis, H. Willems, R. Torfs, and G. Wets, "Impact of timeactivity patterns on personal exposure to black carbon," Atmospheric Environment, vol. 45, pp. 3594 - 3602, 2011.

[23] A. de Nazelle, S. Fruin, D. Westerdahl, D. Martinez, A. Ripoll, N. Kubesch, and M. Nieuwenhuijsen, "A travel mode comparison of commuters' exposures to air pollutants in barcelona," Atmospheric Environment, vol. 59, pp. $151-159,2012$

[24] S. Steinle, S. Reis, and C. E. Sabel, "Quantifying human exposure to air pollutionmoving from static monitoring to spatio-temporally resolved personal exposure assessment," Science of The Total Environment, vol. 443, pp. $184-193,2013$

[25] B. Predic, Z. Yan, J. Eberle, D. Stojanovic, and K. Aberer, "Exposuresense: Integrating daily activities with air quality using mobile participatory sensing," in Pervasive Computing and Communications Workshops (PERCOM Workshops), 2013 IEEE International Conference on, 2013.

[26] (2013) Variable technologies. [Online]. Available: http://www.variabletech.com/

[27] (2013) Wahoo fitness. [Online]. Available: http://www.wahoofitness.com/

[28] V. et al, "Minute ventilation and heart rate relationship for estimation of the ventilatory compensation point at high altitude: a pilot study," Extreme Physiology and Medicine, no. 2:7, 2013.

[29] P. Young, J. Pilcher, M. Patel, L. Cameron, I. Braithwaite, M. Weatherall, and R. Beasley, "Delivery of titrated oxygen via a self-inflating resuscitation bag," Resuscitation, vol. 84, pp. 391 - 394, 2013. 